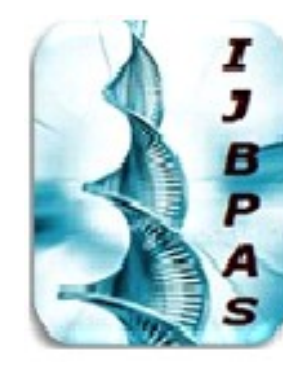

International Journal of Biology, Pharmaey and Allied Sciences (IJBPAS) 'A Bridge Betueen Caboratory and Q ando' WWW.ijbpas.com

\title{
GALLBLADDER INFLAMMATORY POLYPS
}

\section{MOHAMED MOSTAFA ELSHAFEY ${ }^{1}$, LOAI ALHAMMAD ${ }^{1}$, MAJED ALDHUB ${ }^{1}$}

1: Department Of Radiology, King Fahad University, Saudi Arabia

*Corresponding Author: E Mail: drmohamed0126234867@gmail.com

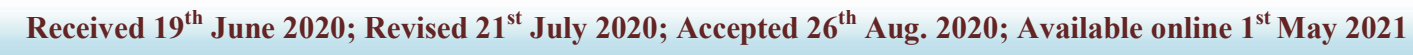

\section{https://doi.org/10.31032/IJBPAS/2021/10.5.5509}

\section{Case Summary}

There is 16 years old male patient complain of recurrent upper quadrant pain, the patient repeated visit ER hospital the abdominal ultrasound is done revealed gall bladder mass so requested to computed tomography (CT) after that Magnetic resonance cholangiopancreatography (MRCP) done.

\section{Imaging Findings}

First abdominal ultrasound is done revealed large polypoid gallbladder mass with internal vascularityno stones. Then CT abdomen with contrast demonstrated large enhanced gall bladder mass so MRCP done to evaluated the mass and biliary duct revealed. The gallbladder is partial distended containing multiple intra-luminal pedunculated masses occupying the body and neck of the gall-bladder demonstrating isointense signal intensity in T1\&T2 with enhancing in post contrast, no bladder wall thickening.

The common bile duct \& intrahepatic bile duct (CBD \& IHBD)are not dilated. After that cholecystectomy and excisional biopsy is done the histopathology revealed gall bladder wall infiltrated by chronic inflammatory-cells mainly eosinophils, also noted are histiocytic, multiple polyposis lesions are identified covered by similar epithelium with intestinal metaplasia.Cores of the polyps is mostly oedematous, focally fibrous. No evidence of malignancy in the examined sections.

\section{Diagnosis}

Chronic cholecystitis, multiple non neoplastic polyps features favor hyperplastic/metaplastic polyps. 


\section{Differential diagnosis}

- Gallstone

- Biliary sludge

- Adenomyomatosis

- Gallbladder carcinoma

- Gallbladder metastases
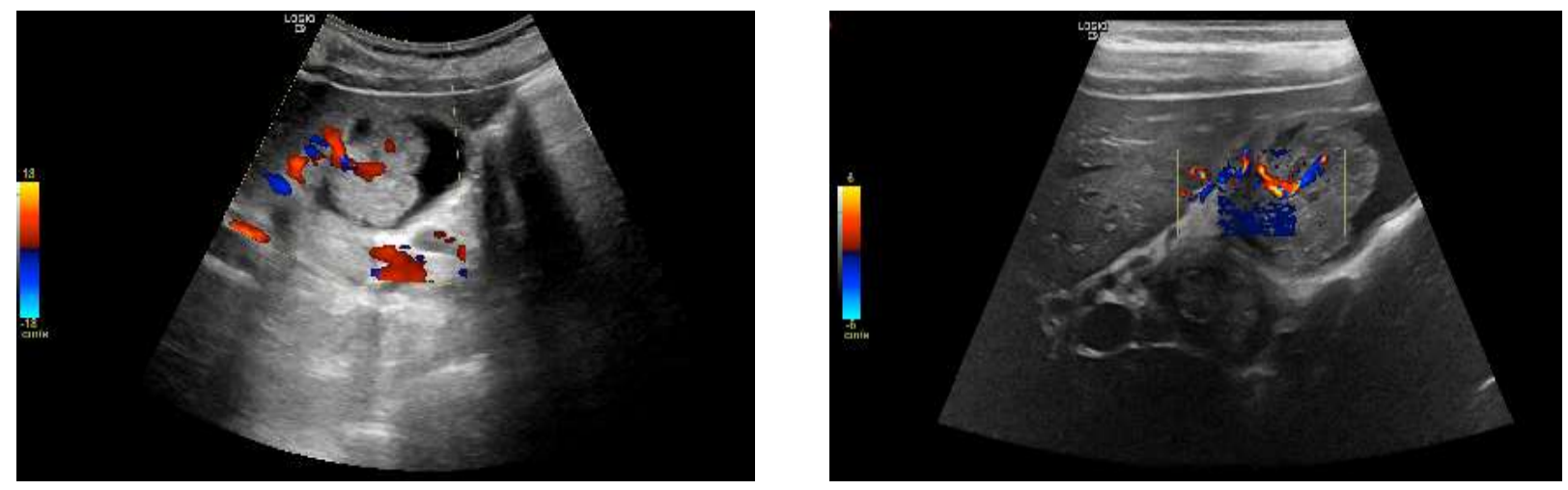

Abdominal ultrasound revealed .The gall bladder shows distended filled with well-defined isoechoic slightly hyperechoic intraluminal large lobulated masses by Doppler shows the mass is feeding by prominent blood supply,
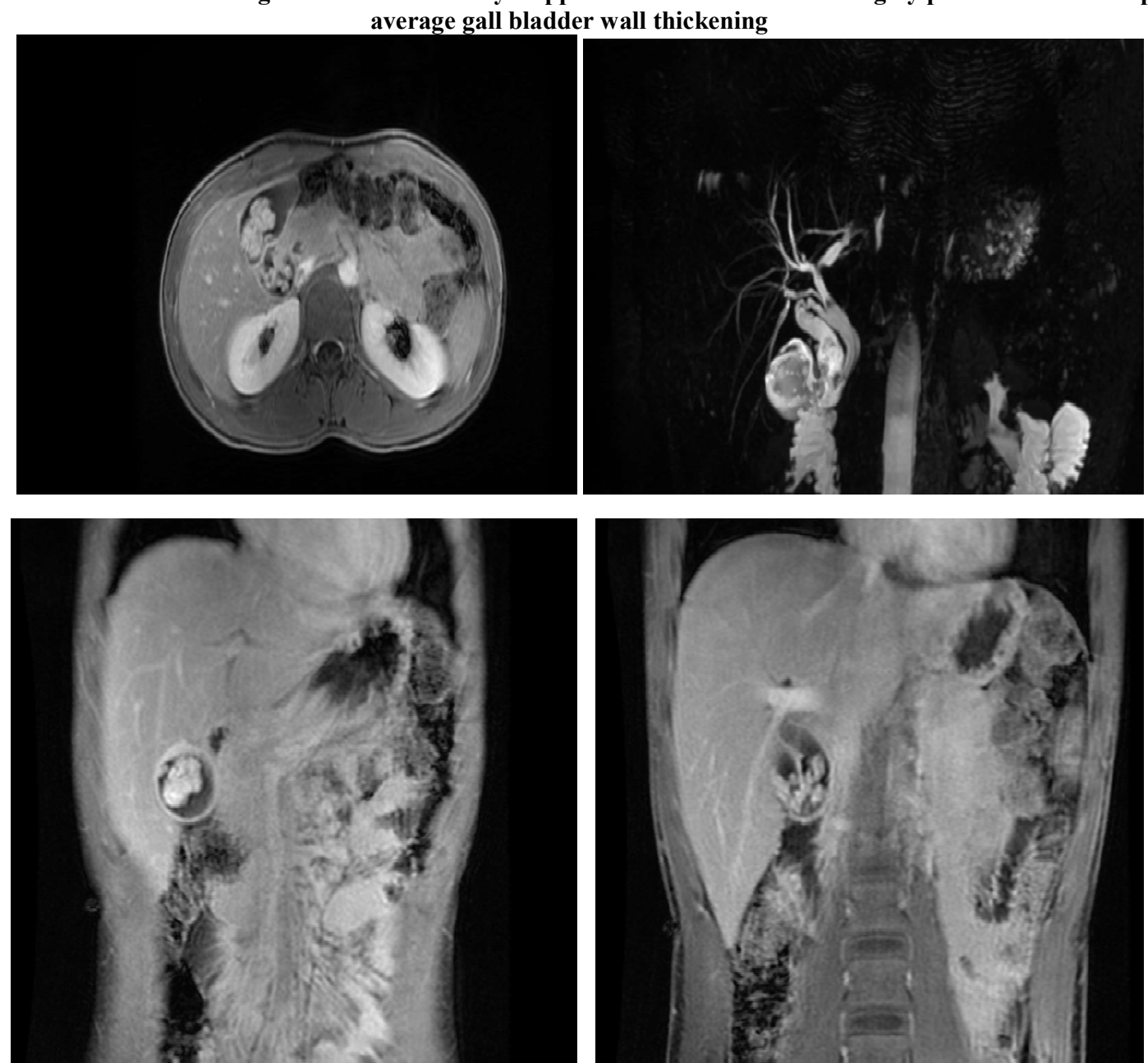

MRCP revealed the gallbladder is partial distended containing multiple intra-luminal pedunculated masses occupying the body and neck of the gallbladder demonstrating isointense signal intensity in T1\&T2 with enhancing in post contrast no bladder wall thickening 


\section{DISCUSSION}

On imaging, the gall bladder polyps (GPS) can be detected by ultrasound, CT. MRI, or positron emission tomography (PET). The ultrasound has high sensitivity for detection of gall bladder lesion and stones superior to both CT and MRI. Ultrasound is the best initial imaging choice for diagnosing GPs, Due to easy, low cost and fast study also have highly specificity and sensitivity [1]. We can use 3.5Mega Hertz (MHZ) conveys abdominal probe to determine size and echogenic and vasculature of the GPS as well we can use 7.5 $\mathrm{MHz}$ linear probe to give us more details about vasculature or the lesion have malignant behavior as ill defied or gall bladder wall infiltration, the lesion is sessile or pedunculated. The gall bladder polyp is isoechoic, have no acoustic shadowing and immobile also in growth into gallbladder lumen [2].

Otherwise gall bladder suspicious mass characterized by fungating infiltrating and wall thickening adjacent to the polypoid lesion, multiple polyps and biliary strictures as well as present of gallstones and stone shadowing which increase the likelihood that the polyp is a neoplastic lesion [2] ultrasound can be distinguish adenocarcinoma from a cholesterol polyp. A cholesterol polyp shows as a mass with isoechoic to the gallbladder wall and with no shadow.
CT is often unable to determined low density gall bladder polyp or small Low density stones also the polyp have low enhanced the same as the rest of gall bladder but if have intense enhancement should be viewed with suspicion, due to it is associated with increased vascularity in malignancy [3].

The CT is used mainly in work up for gallbladder carcinoma, anatomic correlations and for investigating metastases. In MRI Polyps are usually seen as homogeneous low to intermediate signal intensity on T1- and T2-weighted images. They exhibit contrast enhancement that is best seen on delayed images.

Gallbladder inflammatory polyps are a benign subtype of gallbladder polyps, representing $\sim 10 \%$ of all polyps. They appear as a result of chronic inflammation. By far, most gallbladder polyps are benign. Nevertheless, it is important to recognize gallbladder cancer at an early stage, when it may be respectable for cure. Radiologic findings can be used to stratify gallbladder polyps into three groups: those that need no further follow-up, those that require follow-up, and those that should be excised [3]. In addition to the likelihood of malignancy on the basis of imaging findings.

\section{CONCLUSION}

Ultrasound is the golden modality in diagnosis gall bladder polyps and easy 
determined suspicious polyps for excisional biopsy $\mathrm{CT}$ come in next steps for determined metastatic workup.

\section{REFERENCES}

[1] Mellnick VM, Menias CO, Sandrasegaran $\mathrm{K}$ et al. Polypoid lesions of the gallbladder: disease spectrum with pathologic correlation. Radiographics. 2015; 35 (2): 387-99.

[2] Seretis C, Lagoudianakis E, Gemenetzis $\mathrm{G}$ et al. Metaplastic changes in chronic cholecystitis: implications for early diagnosis and surgical intervention to prevent the gallbladder metaplasia-dysplasiacarcinoma sequence. J Clin Med Res. 2013; 6 (1): 26-9.

[3] Chatterjee A, Lopes Vendrami C, Nikolaidis P, Mittal PK, Bandy AJ, Menias CO, Hammond NA, Yaghmai V, Yang GY, Miller FH. Uncommon Intraluminal Tumors of the Gallbladder and Biliary Tract: Spectrum of Imaging Appearances. (2019) Radiographics: a review publication of the Radiological Society of North America, Inc. 39 (2): 388-412. 